\title{
Atuação dos profissionais de saúde em quadros de parada cardiorrespiratória
}

\section{Role of health professionals in cardiac arrest conditions}

Papel de los profesionales de la salud en las condiciones de paro cardíaco

Angélica Cristina Castro Soares ORCID: https://orcid.org/0000-0002-5202-6996

Universidade Castelo Branco, Brasil

E-mail: angelica.enf@outlook.com

Aida Francisca da Silva

ORCID: https://orcid.org/0000-0002-2990-8480

Universidade Iguaçu, Brasil

E-mail: aydaenfermagem2016@gmail.com

Cibele Marques de Lima

ORCID: https://orcid.org/0000-0001-6302-1253

Universidade Iguaçu, Brasil

E-mail: cibele.lima02@gmail.com

Cristiane Alves de Sales

ORCID: https://orcid.org/0000-0001-6293-6902

Faculdade Bezerra de Araújo, Brasil

E-mail: cristiane.salles2303@gmail.com

Fábio Angelo de Medeiros

ORCID: https://orcid.org/0000-0002-2077-1457

Faculdade Estácio de Sá, Brasil

E-mail: fabio.angelo36@gmail.com

Gabriela Alves Santana de Oliveira

ORCID: https://orcid.org/0000-0002-9530-0924

Universidade Iguaçu, Brasil

E-mail: gabrielaalvessoliveira@gmail.com

Inoã da Costa

ORCID: https://orcid.org/0000-0002-1629-0570

Universidade do Grande Rio, Brasil

E-mail: inoagreg1@gmail.com

Isabella Magalhães Barbosa

ORCID: https://orcid.org/0000-0002-7499-0890

Universidade Veiga de Almeida, Brasil

E-mail: issxmagalhaes@gmail.com

Isabela Sant'Anna de Farias

ORCID: https://orcid.org/0000-0003-2933-4947

Faculdade Estácio de Sá, Brasil

E-mail: isabela.2000@ hotmail.com

Janaina Kelly da Silva de Souza de Araújo

ORCID: https://orcid.org/0000-0001-7047-5712

Faculdade Estácio de Sá, Brasil

E-mail: janainakelly.enfermeira@gmail.com

Jéssica Pimentel Gomes da Costa Muchuli

ORCID: https://orcid.org/0000-0002-6182-579X

Universidade Iguaçu, Brasil

E-mail: enfermeirajessicagomes@gmail.com

Larissa Machado Campana Portela

ORCID: https://orcid.org/0000-0003-3248-2924

Universidade Veiga de Almeida, Brasil

E-mail: larissaenfuva@hotmail.com

Letícia Clementino dos Santos

ORCID: https://orcid.org/0000-0002-9316-9029

Faculdade Estácio de Sá, Brasil

E-mail: leticiaenf2@outlook.com

Ronilce Rozendo Amorim

ORCID: https://orcid.org/0000-0003-2291-6055

Faculdade Estácio de Sá, Brasil

E-mail: ronilceamorym@gmail.com

Mariane Marques dos Santos Bongestab

ORCID: https://orcid.org/0000-0002-7097-0497

Faculdade Estácio de Sá, Brasil

E-mail: gersonemariane@gmail.com 


\author{
Marcus Vinícius Braga Esteves \\ ORCID: https://orcid.org/0000-0001-5450-1693 \\ Faculdade Estácio de Sá, Brasil \\ E-mail: estevesbmarcus@outlook.com \\ Marcelo Rodrigues Pessoa \\ ORCID: https://orcid.org/0000-0002-4605-5272 \\ Faculdade Estácio de Sá, Brasil \\ E-mail: marcelo.pesso@hotmail.com \\ Valéria Cristina Brandão Marinho \\ ORCID: https://orcid.org/0000-0002-9344-6161 \\ Faculdade Estácio de Sá, Brasil \\ E-mail: vcbmarinho@gmail.com \\ Mariana Lopes Teixeira \\ ORCID: https://orcid.org/0000-0002-1382-3271 \\ Faculdade Estácio de Sá, Brasil \\ E-mail: marianalopestx@gmail.com \\ Larissa Lessa dos Santos \\ ORCID: https://orcid.org/0000-0002-8947-6691 \\ Faculdade Estácio de Sá, Brasil \\ E-mail: larissalessaa@ @otmail.com
}

\begin{abstract}
Resumo
Introdução: Denomina-se parada cardiorrespiratória (PCR) como a ausência de batimentos cardíacos e apneia. Esse quadro é classificado como uma condição clínica grave que é cada vez mais incidente nas Unidades de Terapia Intensiva, por esse motivo, os profissionais de saúde precisam ser preparados para atuar nesse contexto. Objetivo: Analisar os casos de parada cardiorrespiratória em diferentes setores da assistência. Metodologia: Realizada busca pela Biblioteca Virtual de Saúde (BVS), no mês de julho de 2021. Iniciou-se a busca de materiais que contivessem em seu resumo os descritores em ciências da saúde (DeCS) Enfermeiro; Parada cardíaca; Unidade de Terapia Intensiva. Foi usado o boleador "and" e adotados os seguintes critérios para seleção dos artigos: materiais completos, em língua portuguesa, no formato de artigo e com recorte temporal de dez anos (2011-2021). Resultados: Foram analisados três artigos e a partir da leitura minuciosa foi elaborada a categoria com a temática "Atribuições e desafios encontrados por profissionais de enfermagem no momento da RCP". Considerações Finais: Os problemas diários vividos por profissionais enfermeiros na assistência às vítimas de PCR são vários e entre eles acentua-se a escassez de qualificação dos trabalhadores, a carência de investimentos em educação permanente e a falta de suporte rápido, padronizado e de alta qualidade, são condições que possuem um alto perigo de obstáculos e até morte.
\end{abstract}

Palavras-chave: Enfermeiro; Parada cardíaca; Unidade de Terapia Intensiva.

\begin{abstract}
Introduction: Cardiorespiratory arrest (CPA) is called the absence of heartbeat and apnea. This condition is classified as a serious clinical condition that is increasingly incident in Intensive Care Units, for this reason, health professionals need to be prepared to act in this context. Objective: To analyze cases of cardiac arrest in different care sectors. Methodology: A search was carried out in the Virtual Health Library (VHL) in July 2021. The search for materials that contained in their abstract the descriptors in health sciences (DeCS) was started Nurse; Cardiac arrest; Intensive care unit. The "and" rounding tool was used and the following criteria were adopted for the selection of articles: complete materials, in Portuguese, in article format and with a ten-year time frame (2011-2021). Results: Three articles were analyzed and, based on a thorough reading, the category with the theme "Assignments and challenges encountered by nursing professionals at the time of CPR" was created. Final Considerations: The daily problems experienced by professionals nurses in the assistance to victims of CPA are several and among them, the lack of qualification of workers, the lack of investments in permanent education and the lack of fast, standardized and highquality support is accentuated. are conditions that pose a high danger of obstacles and even death.
\end{abstract}

Keywords: Nurse; Cardiac arrest; Intensive Care Unit.

\title{
Resumen:
}

Introducción: El paro cardiorrespiratorio (CPA) se denomina ausencia de latidos cardíacos y apnea. Esta condición está catalogada como una condición clínica grave y cada vez más incidente en las Unidades de Cuidados Intensivos, por lo que los profesionales de la salud deben estar preparados para actuar en este contexto. Objetivo: Analizar casos de paro cardíaco en diferentes sectores asistenciales. Metodología: Se realizó una búsqueda en la Biblioteca Virtual en Salud (BVS) en julio de 2021. Se inició la búsqueda de materiales que contenían en su resumen los descriptores en ciencias de la salud (DeCS) Enfermera; Paro cardiaco; Unidad de terapia intensiva. Se utilizó la herramienta de redondeo "y" y se adoptaron los siguientes criterios para la selección de artículos: materiales completos, en portugués, en formato de artículo y con un plazo de diez años (2011-2021). Resultados: Se analizaron tres artículos y, a partir de una lectura exhaustiva, se creó la categoría con el tema "Asignaciones y desafíos que enfrentan los profesionales de enfermería en el momento de la RCP". Consideraciones finales: Son varios los problemas cotidianos que 
experimentan los profesionales de enfermería en la atención a las víctimas de CPA y entre ellos se encuentra la falta de calificación de los trabajadores, la falta de inversiones en educación permanente y la falta de un apoyo rápido, estandarizado y de alta calidad. acentuado., son condiciones que plantean un alto peligro de obstáculos e incluso la muerte.

Palabras clave: Enfermera; Paro cardiaco; Unidad de Terapia Intensiva.

\section{Introdução}

Denomina-se parada cardiorrespiratória (PCR) como a ausência de batimentos cardíacos e apneia. Esse quadro é classificado como uma condição clínica grave que é cada vez mais incidente nas Unidades de Terapia Intensiva, por esse motivo, os profissionais de saúde precisam ser preparados para atuar nesse contexto. Geralmente, o enfermeiro é a pessoa que orienta a equipe, como por exemplo: autoriza o início das manobras, checa a monitorização do ritmo cardíaco, solicita a presença do médico de plantão e registra todo o ocorrido no livro do setor. (Zanini et al., 2006)

Deve-se observar o ritmo cardíaco do paciente, pois o mesmo serve como norteador das condutas, podendo ser preciso iniciar diretamente as manobras cardíacas ou recomendado fazer uso do desfibrilador automático que dispara choques elétricos para recuperar o ritmo sinusal. Quando há necessidade de realizar as manobras de reanimação cardiopulmonar, as mesmas devem ser iniciadas o mais rápido possível, devendo ser ritmadas e padronizadas. (Silva et al., 2016)

A parada cardíaca pode ser causada por quatro tipos de ritmos: fibrilação ventricular (FV), taquicardia ventricular (TV) sem pulso - ritmos que requerem choque imediato para reversão do quadro e ritmos de assistolia ou atividade elétrica sem pulso (AESP) - são os ritmos que não recebem a desfibrilação. (Lugon et al., 2014)

A chance de sobrevida para o paciente pode variar de acordo com o local que o mesmo se encontra, caso esteja em um ambiente hospitalar, por exemplo, a manobra geralmente é mais eficiente, pois os funcionários possuem tecnologias de primeira linha que auxiliam na efetividade da assistência. (Silva \& Padilha, 2001)

Já os serviços de urgência e emergência não possuem o suporte e a infraestrutura que um setor hospitalar pode oferecer, porém, a atuação da equipe nessas situações é de extrema relevância. Os profissionais precisam ser competentes para iniciar as manobras básicas de reanimação fazendo com que os batimentos cardíacos sejam restabelecidos evitando lesões em órgãos alvo.

Para que a assistência a um indivíduo nessa condição seja realizada com êxito, há necessidade de constatação precoce dos sinais de parada cardiorrespiratória (PCR), imediato acionamento do sistema de suporte de emergência e efetividade dos protocolos básico e avançado de vida. Os regulamentos que guiam essas práticas em casos de emergência procuram favorecer e contribuir nas medidas frente à PCR. (Barros \& Neto, 2018).

Fica clara a necessidade de acesso às informações para população em geral sobre a rede de sobrevivência. A vontade de ajudar sem entendimento preexistente pode gerar perda de tempo quando se considera o próximo estágio a ser praticado, o que pode causar prejuízos que não podem ser revertidos, especialmente em órgãos alvos, à redução de oxigenação. (Sousa et al., 2021).

A Educação Permanente é um projeto que objetiva modificar e habilitar o cuidado em saúde, as metodologias formativas e as técnicas de instrução em saúde, ressaltando a relevância da qualificação de toda a equipe que atua no campo de saúde, apesar da dificuldade da assistência. (Nogueira et al., 2018)

O presente estudo tem como objetivo analisar os casos de parada cardiorrespiratória em diferentes setores da assistência. O estudo se justifica devido ao número reduzido de pesquisas por profissionais de enfermagem. A partir do exposto fica clara a importância da elaboração de uma revisão de literatura destacando a temática.

A relevância para os acadêmicos de enfermagem se faz com a intenção de informar e buscar uma reflexão sobre a temática, uma vez que será de grande importância esse conhecimento para a assistência realizada por eles no futuro; social por 
levar à sociedade o conhecimento científico ao qual, de costume, ela não teria acesso e para fins de pesquisa, já que outros poderão então fazer uso dos dados encontrados, reunidos e analisados.

\section{Metodologia}

Bardin (2016) relata que a pesquisa qualitativa é aquela que tem fundamento principalmente nas análises qualitativas, caracterizando-a pela não utilização de instrumental estatístico na fase de análise dos dados.

Não é apenas a "pesquisa não quantitativa", tendo desenvolvido sua própria identidade. Assim, visa entender, descrever e explicar os fenômenos sociais de modos diferentes, através da análise de experiências individuais e grupais, exame de interações e comunicações que estejam se desenvolvendo, assim como da investigação de documentos (textos, imagens, filmes ou músicas) ou traços semelhantes de experiências e integrações (Flick, 2009).

O projeto de revisão integrativa visa fazer uma interseção de estudos da mesma linha de conhecimento, com o objetivo de analisar e sintetizar os mesmos, para que se obtenha uma informação mais abrangente de um fenômeno específico, (Cooper,1984).

A revisão integrativa sugere utilizar critérios bem definidos para as fases de coleta de dados, análise; apresentação dos resultados, desde o início da pesquisa, a partir de um protocolo de estudo previamente elaborado e validado (Ganong, 1987).

Para a elaboração deste trabalho abordou-se a proposta de revisão integrativa, que consiste na elaboração de análise abrangente de artigos, obedecendo os critérios de investigação técnico-científico para a coleta de dados, análise e apresentação dos resultados. Os dados obtidos podem sinalizar achados que precisam de mais atenção no meio acadêmico, visando melhorias da prática profissional (Ganong, 1987).

De acordo com Mendes, Silveira e Galvão (2008) a revisão de literatura deverá conter seis etapas: 1- Estabelecimento de hipótese ou questão de pesquisa; 2- Amostragem ou busca na literatura; 3- Categorização dos estudos; 4- Avaliação dos estudos incluídos na revisão; 5- Interpretação dos resultados; 6- Síntese do conhecimento ou apresentação da revisão.

Como tática para identificação e seleção de documentos, a busca foi realizada pela busca da Biblioteca Virtual de Saúde (BVS), no mês de julho de 2021. Iniciou-se a busca de materiais que contivessem em seu resumo os descritores em ciências da saúde (DeCS) Enfermeiro; Parada cardíaca; Unidade de Terapia Intensiva. Foi usado o boleador "and" e adotados os seguintes critérios para seleção dos artigos: materiais completos, em língua portuguesa, no formato de artigo e com recorte temporal de dez anos (2011-2021). Os critérios de exclusão foram os estudos duplicados, desatualizados e com irrelevância para o viés pesquisado neste trabalho.

Destacaram-se 8 artigos com os critérios citados anteriormente, os mesmos procederam-se à leitura detalhada para a construção do exposto, destacando os que responderam ao objetivo tendo como intuito a organização dos dados.

Os documentos foram separados por título, autores, base de dados, ano de publicação, objetivo, método de pesquisa e conclusão. A partir desse momento foi iniciada a análise bibliomética sob forma de categoria através da similaridade de cada um.

\section{Resultados e Discussão}

Os resultados apresentados no estudo foram descritos no Quadro 1 com elementos que compõem os estudos analisados. 
Quadro 1: Características dos artigos analisados no período de 2010 a 2020.

\begin{tabular}{|c|c|c|c|c|c|}
\hline Título & Autoria & Ano & Objetivo & Métodos & Considerações Finais \\
\hline $\begin{array}{l}\text { Hipotermia } \\
\text { terapêutica: Efeitos } \\
\text { adversos, } \\
\text { complicações } \\
\text { cuidados } \\
\text { enfermagem }\end{array}$ & $\begin{array}{l}\text { Lisiane Van Ommeren } \\
\text { Corrêa; } \\
\text { Rosemary Silva da } \\
\text { Silveira; } \\
\text { Joel Rolim Mancia; } \\
\text { Natália Lopes Correa; } \\
\text { Ismael Moron de Souza } \\
\text { Reinhardt; } \\
\text { Valéria Lerch Lunardi; } \\
\text { Rosane Mortari Ciconet. }\end{array}$ & 2014 & $\begin{array}{l}\text { Conhecer os efeitos } \\
\text { adversos } \\
\text { complicações } \\
\text { vivenciadas pela } \\
\text { equipe de saúde e } \\
\text { conhecer } \\
\text { cuidados } \\
\text { enfermagem de } \\
\text { realizados durante a } \\
\text { aplicação } \\
\text { hipotermia } \\
\text { terapêutica. }\end{array}$ & $\begin{array}{l}\text { Abordagem } \\
\text { qualitativa }\end{array}$ & $\begin{array}{l}\text { A hipotermia terapêutica } \\
\text { é possível de ser aplicada, } \\
\text { na realidade das } \\
\text { instituições pesquisadas, } \\
\text { de maneira segura, eficaz } \\
\text { e com baixo custo, } \\
\text { fazendo-se relevante, } \\
\text { entretanto, a realização de } \\
\text { qualificação das equipes, } \\
\text { a fim de esclarecer } \\
\text { dúvidas e favorecer a } \\
\text { adesão e os cuidados } \\
\text { necessários de serem } \\
\text { prestados. }\end{array}$ \\
\hline $\begin{array}{l}\text { Atuação } \\
\text { enfermeiro do } \\
\text { equipe de saúde } \\
\text { durante parada } \\
\text { cardiorrespiratória } \\
\text { em unidade de } \\
\text { terapia intensiva } \\
\text { pediátrica: Proposta } \\
\text { de protocolo }\end{array}$ & $\begin{array}{l}\text { Rodrigo Pereira Costa } \\
\text { Taveira. }\end{array}$ & 2018 & $\begin{array}{l}\text { Elaborar } \\
\text { protocolo } \\
\text { atendimento } \\
\text { assistencial para } \\
\text { atuação da equipe } \\
\text { de enfermagem no } \\
\text { manejo da PCR na } \\
\text { UTI pediátrica. }\end{array}$ & $\begin{array}{l}\text { Estudo } \\
\text { descritivo e } \\
\text { exploratório }\end{array}$ & $\begin{array}{lr}\text { Entrega em sua conclusão } \\
\text { uma proposta } \\
\text { fluxograma com intuito } \\
\text { de favorecer } \\
\text { sistematização }\end{array}$ \\
\hline $\begin{array}{l}\text { Uso do metrônomo } \\
\text { na ressuscitação } \\
\text { cardiopulmonar em } \\
\text { uma Unidade de } \\
\text { Terapia Intensiva }\end{array}$ & $\begin{array}{l}\text { Flávia Silva Ferreira; } \\
\text { Laíne Maria Monteiro } \\
\text { Garrido; } \\
\text { Raquel Chagas Oliveira; } \\
\text { Mariana de Almeida } \\
\text { Moraes; } \\
\text { Cláudia Geovana da Silva } \\
\text { Pires; } \\
\text { Fernanda Carneiro Mussi. }\end{array}$ & 2018 & $\begin{array}{lrr}\text { Relatar a vivência } \\
\text { no uso do } \\
\text { metrônomo durante } \\
\text { as manobras de } \\
\text { ressuscitação } \\
\text { cardiopulmonar em } \\
\text { UTI. }\end{array}$ & $\begin{array}{l}\text { Relato de } \\
\text { experiência }\end{array}$ & $\begin{array}{l}\text { O aparelho não assegurou } \\
\text { a qualidade na RCP. }\end{array}$ \\
\hline
\end{tabular}

Fonte: Autores.

Após análise dos artigos selecionados neste estudo foi construída a seguinte categoria.

\section{Categoria 1: Atribuições e desafios encontrados por profissionais de enfermagem no momento da RCP}

A parada cardiorrespiratória (PCR) é um estado súbito em que acontece a cessação brusca do trânsito sanguíneo e da condução de oxigênio para os órgãos essenciais, diminuindo a habilidade de produzir um curso minúsculo que assegure a plenitude da célula e do tecido, induzindo o contato do desgaste cardíaco, barreira vascular sistematizada e tensão da artéria, com perigo de danos isquêmicos, dentre outros prejuízos. (Corrêa et al., 2018).

No decorrer de uma PCR, o entendimento do local no qual o profissional está introduzido, o reconhecimento e disponibilidade dos artifícios, bem como a rapidez na realização das providências para a ressuscitação cardiopulmonar são essenciais para garantir a sua eficácia. (Ferreira et al., 2018).

O profissional enfermeiro deve atuar de forma integral na assistência à PCR, que vai desde o reconhecimento de uma PCR, começo ou cooperação nas manobras, efetuar intervenções invasivas, participar da organização no cuidado, começando pelo que é aconselhado mundialmente, entre outros. (Taveira, 2018).

Por meio de pesquisas é certificado que os trabalhadores de enfermagem e o enfermeiro exibem uma deficiência significativa sobre as concepções de PCR, reconhecimento de paciente em PCR, ordem do suporte básico de vida (CAB) e drogas a serem aplicadas. Essa deficiência de compreensão pode acarretar eventos que irão intervir sobre todo quadro multiprofissional no momento da PCR. (Taveira, 2018). 
A assistência de uma vítima em PCR na UTI é definida pela carência de aperfeiçoamento da utilização da duração e de práticas e conhecimentos técnicos e científicos. Além disto, a habilidade dos profissionais em dominar o estresse é essencial para a qualidade na RCP em âmbito hospitalar. (Ferreira et al., 2018).

É notado um déficit por parcela dos enfermeiros para identificar a PCR e as ações corretas a serem executadas, ocorrendo até práticas de operações opostas, como por exemplo, manobras executadas na ordem incorreta ou de maneira equivocada, finalizar a massagem inutilmente ao que é sugerido mundialmente. (Taveira, 2018).

O profissional enfermeiro é um interventor no desempenho da PCR. O desenvolvimento do trabalhador e a duração da ação agem no indicador de correções das indagações estudadas. A carência de controle pelo profissional enfermeiro das capacidades necessárias para o comportamento em uma PCR pode transferir ao deslize da equipe multiprofissional, podendo maleficiar o usuário. (Taveira, 2018).

\section{Considerações Finais}

Os problemas diários vividos por profissionais enfermeiros na assistência às vítimas de PCR são vários e entre eles acentua-se a escassez de qualificação dos trabalhadores, a carência de investimentos em educação permanente e a falta de suporte rápido, padronizado e de alta qualidade, são condições que possuem um alto perigo de obstáculos e até morte.

Contudo os profissionais de enfermagem comumente são os primeiros que reconhecem e começam as intervenções de RCP. Assim, as pesquisas analisadas indicam que é de grande relevância o treinamento periódico de profissionais de enfermagem para que eles sejam capazes de oferecer o cuidado e acordo com os guias e as regulamentações atuais.

A partir das pesquisas realizadas para a construção deste estudo, os autores notaram a necessidade de elaborar outras buscas sobre a temática e área envolvidas em questão, aprofundando-se cada vez mais devido à escassez de material existente. Desta maneira, acreditamos que futuramente teremos outros projetos para apresentar e assim, colaborar com a pesquisa, as comunidades acadêmicas e principalmente com a sociedade.

\section{Referências}

Bardin, L. (2016). Análise de conteúdo. Almedina Brasil.

Barros, F. R. B., \& Neto, M. L. Parada e reanimação cardiorrespiratória: conhecimento do enfermeiro baseado nas diretrizes da American Heart Association 2015. Enferm. Foco 2018, 9 (3): 8-12|13.

Cooper, H. M. (1982). Diretrizes científicas para conduzir revisões integrativas depesquisa. Review of Educational Research, 52(2), 291-302.

Flick, U. (2009). Desenho da pesquisa qualitativa. Artmed.

Ganong, L. H. (1987). Integrative reviews of nursing research. New Tork, 10(11), 1-11.

Lugon, A. S., Santos, V. M., \& Farias, L. G. (2014). Atuação do professional enfermeiro frente a parade cardiorrespiratória de acordo com as novas diretrizes. Centro Universitário São Camilo, Itapemirim.

Mendes, K., Silveira, R. C., \& Galvão, C. M. (2008). Revisão integrativa: método de pesquisa para a incorporação de evidências na saúde e na enfermagem. Texto Contexto Enfermagem, 17(4): 758-64.

Nogueira, L. S., Wilson, A. M. M. M., Karakhanian, A. C. M., Parreira, E. V., Machado, V. M. P., \& Mira, V. L. Avaliação dos conhecimentos e habilidades em ressuscitação cardiopulmonar assimilados por profissionais da atenção primária em saúde (Assessment of knowledge and skills in cardiopulmonary resuscitation assimilated by primary health care professionals). Sci Med. 28(1):ID28843.

Santos, L. P., Rodrigues, N. A., Bezerra, A. L., Sousa, M. N., Feitosa, A. N., \& Assis, E. V. (2016). Parada cardiorrespiratória: principais desafios vivenciados pela enfermagem no serviço de urgência e emergência. Revista Interdisciplinar em Saúde, 3(1), 35-53.

Silva, E. L., \& Menezes, E. M. (2005). Metodologia da pesquisa e elaboração de dissertação. (4a ed.).

Silva, R. M., Silva, B. A., Silva, F. J., \& Amaral, C. F. (2016). Ressuscitação cardiopulmonar de adultos com parada cardíaca intra-hospitalar utilizando o estilo Utstein. Revista Brasileira de Terapia Intensiva, 28 (4), 427-435.

Silva, S. C. \& Padilha, K. G. (2001). Parada cardiorrespiratória na Unidade de Terapia Intensiva: Considerações teóricas sobre os fatores relacionados às ocorrências iatrogências. Revista Esc. Enferm., 35(4), 360-365. 
Research, Society and Development, v. 10, n. 13, e293101320789, 2021

(CC BY 4.0) | ISSN 2525-3409 | DOI: http://dx.doi.org/10.33448/rsd-v10i13.20789

Sousa, M. A., Mota, R. V., Gomes, A. C., Lima, R. N., Oliveira, S. G., \& Freitas, R. W. Atendimento ao adulto em parada cardiorrespiratória: intervenção educativa para estudantes leigos. Enferm Foco. 2021,12(2):360-4. Fortaleza, CE.

Zanini, J., Nascimento, E. R., \& Barra, D. C. (2006). Parada e reanimação cardiorrespiratória: Conhecimentos da equipe de enfermagem em Unidade de Terapia Intensiva. Revista Brasileira de Terapia Intensiva, 18(2), 143-147. 